\title{
The Use of Data Sources of Medication Information - a Finnish Primary Care Organization in the Light of National e- Health Scenarios
}

\author{
Eeva Aarnio, Reetta Raitoharju \\ Turku School of Economics, Information Systems Science \\ Rehtorinpellonkatu 3,FI-20500 Turku, Finland \\ \{Eeva.Aarnio, Reetta.Raitoharju,\}@tse.fi
}

\begin{abstract}
Many areas of the healthcare sector are information-rich and data-intensive, and often lack of time is a problem. Patient-specific medication information is often seen as highly important part of patient data for patients' safe treatment and therefore the availability of it should be guaranteed. The aim of this paper is to study healthcare professionals' perceptions of their utilization of sources of medication information and to assess it in the light of national e-Health scenarios using a Finnish primary care organization as a case study. The healthcare professionals reported frequent use of the patient as a source of information as they could not be convinced of the correctness of the medication lists in the electronic patient record. The future e-Health solutions should be usable and guarantee the correctness and completeness of the medication information if the clinical workers are expected to use them. The valuable information provided by the patients could be also exploited more efficiently in the future.
\end{abstract}

\section{Introduction}

Effective use of information technology (IT) is found to be important to healthcare sector's success [1]. The significance of IT might stem from the fact that many areas of the healthcare sector are highly information-rich [2,3] and data-intensive [4] in nature. A lot of information is produced, used and archived. Clinicians need various

Please use the following format when citing this chapter:

Aarnio, E., Raitoharju R., 2008, in IFIP International Federation for Information Processing, Volume 286; Towards Sustainable Society on Ubiquitous Networks, eds. Oya, M., Uda, R., Yasunobu, C., (Boston: Springer), pp. 209-219. 
types of information in their everyday work. The needed information includes patient data, population statistics, medical knowledge, logistic information and social influences [5]. The information is often located in dispersed resources and the healthcare professionals must find the appropriate pieces of information, and in addition, ensure that the information is accurate [2]. The lack of time is also found to be one of the factors affecting the search. Pressures on time often lead to inadequate choice of resources [6]. There are several factors that promote successful information seeking in clinical settings, e.g. convenience of access, habit, reliability, high quality and speed of use to mention some [7]. However, not even the development of medical informatics has fulfilled the expectations to provide the healthcare professionals with timely, accurate, and appropriate information [8].

The past 40 years have been called even as a "drug explosion" [9]. Despite the fact that drugs are prescribed to improve patients' health and have often positive effects, there are many risks in the complex process of prescribing them [10]. Problems related to drugs include for instance under-dosing and polypharmacy. Therefore the healthcare professionals dealing with prescribing in their daily routines should be given support ensuring the availability of required information.

The topic studied in this paper, medication information, refers to the information about individual's medication regimen: the generic and commercial name of the drug, the dosage, and the use indication. It also covers the risks related to the patient's treatment, e.g. patient's drug allergies. As medication information is patient-specific data, this paper concentrates mainly on the assessment of healthcare professionals' use of the patient data and not on the use of other type of prescribing information (e.g. therapeutic agents or drug prices) that could be achieved from resources open for almost any healthcare professional, like textbooks or electronic sources.

The objective of this paper is to study healthcare professionals' perceptions of their utilization of written and verbal sources of medication information and to assess it in the light of national e-Health scenarios using a Finnish primary care organization as a case study. Bringing together the expert and clinical workers' points of view, the paper aims at answering the following questions:

- What are the healthcare professionals' main verbal and written data sources of medication information and why?

- What could be said about the healthcare professionals' utilization of the data sources in the light of the future e-Health scenarios in Finland?

By defining healthcare professionals' self-perceived use of information sources, we hope to increase the knowledge on how healthcare professionals really utilize sources of information currently, what could be the future possibilities and what should be taken into account when designing the national level archiving solutions.

\section{Methods}

The study consists of two data collection phases. First, a data collection was conducted in a primary care organization consisting of one main health center and dispersed sub-units within one municipality. The primary care health centers in Finland are re- 
quired by law to offer comprehensive primary health care services to the population of the municipality or other fixed area. The physicians working at the health centers are often general practitioners [11]. In this case, 10 healthcare professionals, 5 physicians and 5 nurses from different primary care units were interviewed. The interviewed were chosen based on the proposition of each organization's responsible person among those providing clinical care to be able to assess the real use of sources of medication information.

The interviewed physicians worked mainly in the daytime and treated patients from a fixed area on 15-minutes, pre-booked visits. There is also a 24-hour on-call service at the main health center that offers convenient walk-in care. The same physicians working in the sub-units had also couple of times a month shifts in the 24-hour on-call service. The interviewed nurses' tasks included for instance regular diabetes and blood pressure controlling but they did not have regularly shifts in the on-call service. Electronic patient record (EPR) has been in use in all the units of the case organization since 1999. One researcher with a varying group of other researchers conducted all the interviews in the primary care organization. All the interviews lasted at least one hour and were recorded and transliterated.

The second data collection included 5 interviews of professionals with clinical work experience and/or involvement in healthcare sector national level information system development (e.g. as key members of advisory boards). The experts were chosen to the interview because of their position and potential to provide accurate information on national level plans, as there is not a lot of written information available on the unfinished process. Some of these interviews were conducted as the earlier mentioned and some by email. The same list of questions that was asked in the face-toface interviews was sent as an attachment. The people interviewed by email wrote their answers on the attachment and returned it. As the interviews were also transliterated, all the data was analyzed question by question using written/transliterated material. The data analysis of both parts was conducted by the author involved in all the interviews.

\section{Related Research: Healthcare Professionals' Sources of Information}

Clinicians' sources of information have been quite widely studied; however, remarkable part of the research concentrates on the use of sources open for almost any healthcare professional [9] or of sources to guide clinical practice [12]. In addition, those articles dealing with patient data describe often only physicians' information seeking. Gorman [5] has studied physicians' information needs. He has classified types and usual sources of information. According to him, the usual sources of patient data are the patient, her/his family and friends, and the medical record. Based on their survey, Brown, et al. [13] found that the three most usual sources of information were 1) the bedside flow sheet, 2) conversations with residents, and 3) conversations with nurses.

The sources of information probably vary depending on the special area and type of healthcare organization because of the special features of the organizations. For in- 
stance, intensive care units (ICUs) have been found more stressful places to work than non-ICUs [14]. In the emergency department (ED), the patients are often in critical condition and the information should be found as rapidly as possible. The need for quickly gather the relevant pieces of information means that the team members need to work closely together [2]. An important factor in choosing resources is that the use requires minimal cost to obtain because usually the lack of time is the reason that impedes information search [7].

\section{$4 \quad$ National level e-Health Plans for Patient Information Management}

In Finland, there is a universal healthcare system and public healthcare is available to all residents for free or the most, for a nominal fee. Primary care is provided by municipal health centers from which the patient is referred to specialized hospital care, if required. The private healthcare system is very small and for instance private healthcare insurances are not common. The public healthcare is financed largely through local taxes. Prescription drugs are sold in private-owned, strictly regulated pharmacies and reimbursed by The Social Insurance Institution of Finland, "Kela", depending on the severity and chronic nature of the disease.

There is a national level plan in Finland to guarantee smooth exchange of the patient information between different types of healthcare sector organizations. The authority in charge of the development of national level solutions for "alwaysavailable" patient information is the Social Insurance Institution, Kela. Kela contracts private companies based on tendering to execute the development in practice.

The information on patients' medication is often mentioned to be one of the most important parts of the patient information. The first part of the national plans aims at developing an electronic prescription (e-prescription) and an archive for all the eprescriptions. The piloting of the e-prescription is expected to start in late 2008. At the first phase the e-prescription archive will include all the written prescriptions, however, only if the patient permits the archiving. The prescriptions will mainly be those of outpatients' because there will be no e-prescriptions written for inpatients on the medications taken on the ward. One advantage of the e-prescription archive will be that the information on the medications the patient has really bought from the pharmacy will be available. At least at the first phase, the e-prescription archive will not include for instance information on the patients' drug allergies or other risks related to the patient's medication-taking. In any case, the development of the eprescription archive will probably continue after the implementation of a "goodenough" e-prescription archive. After the e-prescription archive, the next challenge is to solve the question marks related to the management of permissions asked from the patients for the use of their patient information in treatment. The following phase covers the exchange of x-rays.

As the e-prescription archive includes only information on the prescriptions, there will be another archive including other patient-specific information and also more extensive information on patient's medications. The other archive, called here as "eArchive" is still at a very early development phase and therefore all possible ideas for 
the development are current. Also citizens' role as a provider of information is planned to be taken into account and there is under planning a portal or similar where the citizens could, for instance, complete information on the over-the-desk medications they are taking or their medication-taking practice. At some, quite early phase, the citizens will have the possibility to see the prescriptions written to them from the e-prescription archive through an interface that is still under planning.

In the complex process of exchange of patient information, there are some issues impeding the development of information exchange and the use of information. The issues with great importance are related to the technical and legal ones. In accordance with the current legislation, for instance the nurses will not have the right to look at patients' information from the database while they are often responsible for administering medications to the patients. Also data from the occupational health will be still excluded from the information available for healthcare professionals in other areas. The technical issues are mainly related to the different EPR systems used in different healthcare organizations.

\section{$5 \quad$ Results}

\subsection{Physicians' Sources of Medication Information}

The part of medication information that was most important for the physicians, was patient's current medication; what medications he/she really takes regularly. Interviewed primary care physicians reported frequent use of the patient or his/her representative, often a family member, as a source of medication information.

"The patient her/himself has a quite important role, because he/she knows, what he/she has taken, if remembers."

The practice to obtain the information varied but some patients had the medication list on a piece of paper and those using a pillbox had it behind the box. Two physicians described the way they usually get the medication information from the patients as follows:

\footnotetext{
"Some patients come with a self-written list that covers the medications they have taken."

"There is a card behind the pillbox where is penciled the name of the drug, when and in which part of the pillbox it should be administered and based on that one could conclude, what the patient has been taken. Unfortunately, that piece of paper is the most reliable source despite the medication lists of the EPR."
}

For instance Brown, et al. [13] have stated that physicians prefer verbal communication from written notes but at least in this case patient was used as a source because there was no other choice, or the patient needed to confirm that the information achieved from other source was correct. At the time of the interviews, the case organization did not have any precisely defined place in the patient record where all the medications would have been in order. Therefore the list where prescribed medications should have been included often also included already finished courses of medications. In addition, the currently taken medication was recorded on some other leaf, 
for instance on the one updated by the homecare nurses. As one of the physicians put it:

"It [the EPR ] is full of different lists but there is no guarantee of the correctness."

Mostly because of the above-mentioned reasons, EPR was the primary source of information only when patient did not use any private sector health center, had not been in hospital care, and visited regularly the same public sector physician. In those cases physicians knew, on which leaf patient's up-dated medication information was. A physician with a system of her own describes the situation:

"Hmm, I have my own system, my own way to do it, that may not be the same of the other 69 primary care physicians.-- I update continuously a summary that includes patient's medications. - - That is the most important for me, but quite a few physicians use it. I do wonder how they manage to get the information within 400 pages of patient information."

The information on changes made in patient's medication during hospital care usually came to health center but situations when it was never received were also reported. If patient had been in hospital care or had private sector visits meanwhile, and he/she forgot to tell to the physician about them, the treatment decisions could have been made based on outdated information. As mentioned earlier, the information neither from occupational health nor from the mental healthcare was available. Therefore physicians acted even as detectives when figuring out patients' overall medication regime:

"...of course there is such a key, where you can see patient's appointments, ah, you know, if he/she's got appointments also at the mental health clinic, then you understand to ask, if the patient takes any psychiatric medications."

The use of the EPR as a source was also difficult when the system was down. As the EPR had already been in use for years, paper-based records were required rarely. However, some results were still exchanged on paper between organizations, for instance the ECG graphs. Other use of paper-based archives was related to the benefits paid by the public authorities:

"Then [the paper-based archives are used], when patient needs physician's statement for special reimbursement of some medications, we start digging around, what was the history."

Despite the problems arisen from the sometimes challenging use of patients' medication information, the interviewed physicians reported only an infinitesimal amount of severe cases of polypharmacy or other dangerous, medication-related situations. Those reported were mostly related to the interactions caused by some mental health medications or to the generic substitution; the patients did not always realize they were taking a double dosage of some medication on different commercial names if they had renewed the prescriptions in different organizations.

The patient was an important source of her/his own medication information because he/she often had information that no one else could tell, for instance the medication-taking practice. Patients could be perhaps empowered and their role strengthened by sharing their own information through a portal or similar. The interviewed physicians had mainly a positive attitude to the possibility that citizens could look at their own information from an archive. However, they were also aware of the fact that without the required knowledge, many questions would arise and there should be someone to answer those. 
Though this paper assesses individuals' medication information, a reference to other than patient-specific information is required. The interviewees often mentioned internet as a source of information when treating the patient. An important source for the interviewees was a webpage maintained by the Finnish Medical Society Duodecim. The interaction database and the guide on all the medications sold in Finland, Pharmaca Fennica, are available on the page.

\subsection{Nurses' Sources of Medication Information}

The interviewed nurses usually needed patients' medication information on regular control visits. Those controls included diabetes or blood pressure controls, or were related to the use of blood thickening medication or vaccinations. As the patients were often sent to the controls after having visited a physician, the nurses usually found the required information easily from the EHR. The interviewed nurses did not have any problems reading the physicians' notes from the EHR and they thought they would not have had use for any other source of information.

The nurses also used patients as a source of information and usually found them reliable for providing the information they needed, as could be seen from the following quotations:

\footnotetext{
"The patient actually is the primary [source of information] and besides that we lean on the patient information from the EPR."

"He/she [the patient] provides the information if he/she has used anything [medications] or visited another physician than her/his own here at our health center."

"We need to ask from the patients and trust the information."
}

The nurses' tasks were mainly related to one or few of the patients' medications at a time. The main reason for that might be that the nurses are not responsible for the patients' overall medication regime. This could be noticed from the following quotation answered to the question, whether they have problems with patients that get prescriptions from other organizations:

"Well, I don't know, it's probably [a problem] for the physicians but not for us because we do not prescribe anything."

Their role in managing patients' overall medication information was usually advisory in nature. Therefore also the nurses told that important sources of medicationrelated information for them were web pages maintained by trusted administrators.

\subsection{Expert Views on Current Situation and Future Development}

According to the interviewed experts involved in the national level IT development projects in Finland, the schedule of the projects is often really tight. Some of them also stated, that the co-ordination of the activities has not always been the best possible. In the interviewed experts' opinion, the current environment for developing e-Health solutions in Finland is shaped by the difficulty of combining the "old" electronic patient records and other information systems with the new technology. Based on the expert opinions, a concrete problem is that in many patient record systems there is a non-structured medication list that does not enable the exchange of information between organizations easily. 
Another mentioned issue that affects the development of all the e-Health solutions in Finland is how to solve the question of patient's consent that authorizes the healthcare professional to use her/his electronic patient information in treatment decisions. The current law is not very specific about the nature of the consent. However, there have been discussions that in practice patient should be able to recognize exactly to whom, what and why her/his patient data is used. It has been seen as a question of legal protection.

Depending on their task at the national level development projects, the experts were convinced that the issues they were developing would be of great importance for the clinical workers. The e-prescription archive, for instance, would bring available information on what medications patient really buys from the pharmacy. However, they realized that the significance of the developed systems for clinical work was remarkably dependent on the usability of the systems, and on the legal issues.

The citizens' involvement in information providing in the future was seen as a possibility but some experts highlighted that the citizens' portal should be separate from the one where healthcare professionals record the patient data. According to law, it is currently even impossible that patients could add some information in the archives. However, most of the experts were convinced that the patients will have some kind of user interface in the future for their medication information management.

\subsection{The Current and Future Sources of Medication Information}

Part of the medication information required for patient's treatment is such in nature that though there was a portal making it possible for the individual to provide information, only the healthcare professionals should be authorized to record it in the archive. However, based on the healthcare professionals' and experts' views, the patient could bring some additional information. Table 1 summarizes the data sources of medication information currently used by the healthcare professionals and gives an idea of possible additional sources based on the expert interviews.

Table 1 shows that the future e-Archive would have an important role in managing patients' medication information crucial for their treatment. However, the solution is far from the implementation phase. An archive that would technically make it possible to use the information would probably be of good help for the healthcare professionals. The information of occupational health would still stay out of reach at a primary care center.

\section{Discussion}

The objective of this paper is to study healthcare professionals' perceptions of their utilization of written and verbal sources of medication information and to assess it in the light of national e-Health scenarios using a Finnish primary care organization as a case study. Both, the interviewed physicians and nurses used patient often as a primary source of information. The physicians trusted the patient because they could not be convinced of the correctness of the medication lists in the EPR. Unlike the interviewed physicians, the nurses did not report having problems using the EPR as a 

ion in the Light of National e-Health Scenarios

source of patients' medication information. That was probably because they do not have the responsibility for the patients' overall medication and they do not prescribe any medications. Based on experts' opinions, the issues with most effect on the development of e-Health solutions in Finland are related to the legal and technical issues.

Table 1. Data sources of medication information currently used by the healthcare professionals and possible additional sources of medication information

\begin{tabular}{|c|c|c|}
\hline $\begin{array}{l}\text { Required medication in- } \\
\text { formation }\end{array}$ & $\begin{array}{l}\text { Current sources of medication } \\
\text { information }\end{array}$ & $\begin{array}{l}\text { Possible additional sources of } \\
\text { medication information in the } \\
\text { near future }\end{array}$ \\
\hline $\begin{array}{l}\text { Patient's current medica- } \\
\text { tion }\end{array}$ & $\begin{array}{l}\text { Patient or her/his representa- } \\
\text { tive, EPRs of different organi- } \\
\text { zations }\end{array}$ & $\begin{array}{l}\text { e-prescription archive (to } \\
\text { some extent, will not include } \\
\text { for instance in-patients' medi- } \\
\text { cations), e-Archive }\end{array}$ \\
\hline $\begin{array}{l}\text { Medication-taking prac- } \\
\text { tice of patient }\end{array}$ & Patient & $\begin{array}{l}\text { Portal or similar for patient } \\
\text { self-reporting on medication- } \\
\text { taking }\end{array}$ \\
\hline $\begin{array}{l}\text { Delivery information of } \\
\text { the medications patient } \\
\text { has bought from the } \\
\text { pharmacy }\end{array}$ & $\begin{array}{l}\text { Patient or her/his representa- } \\
\text { tive }\end{array}$ & $\begin{array}{l}\text { e-prescription archive (only } \\
\text { the outpatients), e-Archive }\end{array}$ \\
\hline $\begin{array}{l}\text { The diagnosis related to } \\
\text { the medication }\end{array}$ & $\begin{array}{l}\text { EPRs of different healthcare } \\
\text { organizations }\end{array}$ & e-Archive \\
\hline $\begin{array}{l}\text { Risks related in patient's } \\
\text { medication-taking }\end{array}$ & $\begin{array}{l}\text { Patient or her/his representa- } \\
\text { tive, EPRs of different health- } \\
\text { care organizations }\end{array}$ & $\begin{array}{l}\text { e-Archive, portal or similar } \\
\text { for patient self-reporting }\end{array}$ \\
\hline $\begin{array}{l}\text { Prescriber of the medica- } \\
\text { tion, time and place }\end{array}$ & $\begin{array}{l}\text { Patient or her/his representa- } \\
\text { tive, EPRs of different health- } \\
\text { care organizations }\end{array}$ & $\begin{array}{l}\text { e-prescription archive (only } \\
\text { the out-patients), e-Archive }\end{array}$ \\
\hline $\begin{array}{l}\text { Patient's medication his- } \\
\text { tory }\end{array}$ & $\begin{array}{l}\text { Patient or her/his representa- } \\
\text { tive, EPRs of different or- } \\
\text { ganizations }\end{array}$ & $\begin{array}{l}\text { e-prescription archive (only } \\
\text { the out-patients), e-Archive }\end{array}$ \\
\hline $\begin{array}{l}\text { Other medication-related } \\
\text { information }\end{array}$ & $\begin{array}{l}\text { Web pages maintained by } \\
\text { trusted administrator, e.g. } \\
\text { Medical Society Duodecim }\end{array}$ & $\begin{array}{l}\text { Web pages maintained by } \\
\text { trusted administrator, more } \\
\text { tightly connected to the views } \\
\text { of healthcare professionals }\end{array}$ \\
\hline
\end{tabular}

This study may have several limitations. First of all, it is based on the selfreporting by the healthcare professionals and other experts. Second, the number of interviews is limited. However, more or less the same issues appeared in all the interviews. Third, the study consist only interviews of primary care healthcare professionals. Therefore the study results might be different if the data collection had been conducted in another type of unit, e.g. in an emergency department (ED) or at hospital settings. The results are tough at least partly consistent with earlier studies $[5,13,15]$ investigating physicians' information sources, however, the focus of this study was more narrow than in those studies. As the idea was to increase knowledge on one organization's medication information sources and the future possibilities, the study do 
provide a glimpse into the current and future practice of Finnish healthcare professionals' information seeking.

Those times when healthcare professionals were said to be resisting the use of computers are over, at least in Finland. The primary healthcare professionals used patients as a source of medication information despite the EPRs have already been in use for several years in the case organization but the reason for that was other than just resisting new technology. This fact highlights the importance of the future eHealth solutions especially in the sense that just any electronic solutions may not be usable if one cannot trust in the correctness and completeness of the data provided. Neither should patients' role as self-reporting information providers be underestimated as they have currently an essential role and some parts of the medication information could be provided only by them. The patients might complete their medication information in some portal and that would leave more time for other treatment-related issues on physicians' appointments. In the case organization, the nurses also used medication information independently. Therefore it would be important to assure that the future e-Health solutions will not be out of their reach because of law.

It is highly probable that the future e-Health solutions will open up new possibilities for the healthcare professionals when it comes to completing the patient's medication information. Brown, et al. [13] stated in their study, that replicating the paper world in an electronic format will not be reasonable without understanding why the those papers are used as they are being used. The same thing should be noticed here; the developed archives should be at least as good as the earlier used sources of information.

\section{Acknowledgement}

The authors want to express their gratitude to the Finnish Funding Agency for Technology and Innovation. The study has been conducted during FinnWell-funded project called Management of Medication Information.

\section{References}

1. Chiasson, M., Reddy, M.C., Kaplan, B., and Davidson, E.: Expanding multi-disciplinary approaches to healthcare information technologies: What does information systems offer medical informatics?, International Journal of Medical Informatics (2007), Vol.76, No.S1, pp. S89-S97

2. Reddy, M.C. and Spence, P.R.: Collaborative information seeking: A field study of a multidisciplinary patient care team, Information Processing \& Management (2008), Vol.44, No.1, pp. 242255

3. Reddy, M.C., Pratt, W., Dourish, P., and Shabot, M. Asking Questions: Information Needs in a Surgical Intensive Care Unit, Proceedings of the American Medical Informatics Association Fall Symposium AMIA'02. San Antonio, TX 2002.

4. Hagland, M.: Intensive Care: The Next Level for IT, Health Management Technology (1998), Vol.19, No.13, pp. 18 (6 pages)

5. Gorman, P.N.: Information Needs of Physicians, Journal of the American Society for Information Science (1995), Vol.46, No.10, pp. 729-736 
The Use of Data Sources of Medication Information - a Finnish PrimaryCare Organizat ion in the Light of National e-Health Scenarios

6. Ely, J.W., Osheroff, J.A., Ebell, M.H., Chambliss, M.L., Vinson, D.C., Stevermer, J.J., and Pifer, E.A.: Obstacles to answering doctors' questions about patient care with evidence: qualitative study, British Medical Journal (2002), Vol.324, No.7339, pp. 710 (7 pages)

7. Dawes, M. and Sampson, U.: Knowledge management in clinical practice: a systematic review of information seeking behavior in physicians, International Journal of Medical Informatics (2003), Vol.71, No.1,pp. 9-15

8. González-González, A.I., Dawes, M., Sánchez-Mateos, J., Riesgo-Fuertes, R., Escortell-Mayor, E., Sanz-Cuesta, T., and Hernández-Fernández, T.: Information Needs and Information-Seeking Behavior of Primary Care Physicians, Annals of Family Medicine (2007), Vol.5, No.4, pp. 345352

9. McGettigan, P., Golden, J., Fryer, J., Chan, R., and Feely, J.: Prescribers prefer people: The sources of information used by doctors for prescribing suggest that the medium is more important than the message, British Journal of Clinical Pharmacology (2001), Vol.51, No.2, pp. 184-189

10. Kuperman, G.J., Bobb, A., Payne, T.H., Avery, A.J., Gandhi, T.K., Burns, G., Classen, D.C., and Bates, D.W.: Medication-related Clinical Decision Support in Computerized Provider Order Entry Systems: A Review, Journal of the American Medical Informatics Association (2007), Vol.14, No.1, pp. 29-40

11. Engeström, Y.: Objects, contradictions and collaboration in medical cognition: an activitytheoretical perspective, Artificial Intelligence in Medicine (1995), Vol.7, No.5, pp. 395-412

12. Oliveri, R.S., Gluud, C., and Wille-Jorgensen, P.A.: Hospital doctors' self-rated skills in and use of evidence-based medicine - a questionnaire survey, Journal of Evaluation in Clinical Practice (2004), Vol.10, No.2, pp. 219-226

13. Brown, P.J., Borowitz, S.M., and Novicoff, W.: Information exchange in the NICU: what sources of patient data do physicians prefer to use?, International Journal of Medical Informatics (2004), Vol.73, No.4, pp. 349-355

14. Alvarez, G. and Coiera, E.: Interdisciplinary communication: An uncharted source of medical error?, Journal of Critical Care (2006), Vol.21, No.3, pp. 236-242

15. Coiera, E.: When Conversation Is Better Than Computation, Journal of the American Medical Association (2000), Vol.7, No.3, pp. 277-286 